\title{
Digital Media, Technologies and Scholarship: Some Shapes of eResearch in Educational Inquiry
}

\author{
Lina Markauskaite \\ University of Sydney
}

\begin{abstract}
This paper discusses some recent developments in digital media, research technologies and scholarly practices that are known under the umbrella term of "eResearch". Drawing on conceptual ideas of digital materialism, epistemic artefacts and epistemic tools, this paper discusses how the digital inscription of knowledge and knowing could change the nature of knowledge work in educational research and inquiry. This paper argues that eResearch challenges the conventional divide between "monological" and "dialogical" research practices and provides opportunities to create "trialogical" ways of inquiry. These trialogical practices involve not only the collaborative development of answers to research questions, but also require explicit attention and development of new digital epistemic infrastructures - digital resources, software and conceptual tools and social structures. Our limited understanding about educational knowledge building practices is one of the major challenges for further advancement of educational research.
\end{abstract}

\section{Introduction}

The last three decades have been marked by the gradual digitalisation of human culture, knowledge and learning. Evolving digital media and technologies - such as computers, the internet and mobile devices - have been constantly generating new waves of promises and fads. Concurrently, techno-optimistic visions about the egalitarian knowledge society, lifelong learning and the digitally savvy net generation are periodically being offset by scepticism suggesting that these digital developments are just reproducing existing patterns of power, inequalities and illiteracies (cf. Bennett, Maton, \& Kervin, 2008; Cuban, 2001; Prenksy, 2001; van Dijk, 2005; Wyatt et al., 2000).

Researchers in diverse fields, such as philosophy, sociology, psychology and education, have perceptively noticed this digital shift and turned their scholarly attention to the 
implications of digital media and technologies on the foundational notions of education, and teaching and learning practices. Cross-national studies on Information and Communication Technologies (ICT) in education (Law, Pelgrum, \& Plomp, 2008); the learning sciences and technology research on how people learn (Bransford, Brown, \& Cocking, 1999; Sawyer, 2006) and scholarly debates over the "digital literacies", "digital natives" and "online identities" (Bennett et al., 2008; Greenhow \& Robelia, 2009; Lankshear \& Knobel, 2008) are just the tip of the iceberg of scholarly knowledge produced in this field.

A similar digital shift is occurring in research practices (Jankowski, 2009; Schroeder, 2007). E-journal databases, internet search engines, email and other digital media and technologies have become the mainstay of scientific inquiry routines. Further investments into creating special advanced-technology research infrastructures and services - often known in Australia under the umbrella term eResearch ${ }^{1}$ - have been accompanied by a wave of grand visions and sharp debates over the potential of digital media and technologies to transform the ways in which research and scholarship are carried out (cf. Atkins et al., 2003; Borgman, 2007; Hine, 2006; NCRIS Committee, 2008). As the Australian eResearch vision puts it, the transformation process being enabled by advanced and innovative ICT, "offers the power to undertake research on a scope previously unattainable, to work collaboratively and globally in a way not previously possible, and to improve existing research" (DEST, 2006, p. 7). This initial attention on well engineered eResearch infrastructures for "big science" has been followed by the emergence of more participatory "cloud" technologies and Web 2.0 applications - such as GoogleDocs and Facebook - and new hopes that eResearch could induce more open and more democratic forms of research practice (Greenhow, Robelia, \& Hughes, 2009; Schleyer et al., 2008).

The importance of new scientific practices in education and student learning has been generally well acknowledged (e.g., Borgman et al., 2008; CRA, 2005; Underwood et al., 2008) - but admittedly this has received less attention in the Australian educational context. Some efforts have been also made to use eResearch for educational research (e.g., Carmichael, 2007; Romero \& Ventura, 2007). Nevertheless, educational researchers, with only a few exceptions (viz. Eisner, 1997; Greenhow et al., 2009; Smeyers \& Depaepe, 2007; Voithofer, 2005), have been rather slow embracing and exploring new ways of doing educational research in their intellectual debates.

How does the digital inscription of data, inquiry tools and interactions change the nature of knowledge and knowing? How does the digital inscription of learning change the nature of research questions and practices in educational research? Finally, how does eResearch affordances change the ways in which educational research knowledge is (and could be) constructed and communicated? 
The questions posed here are large and complex; and, in this paper, I expand upon several important facets only. I argue that the shift to digital inscription of knowledge and knowing challenges the conventional division between monological and dialogical research practices and provides an opportunity to engage into - what Paavola and Hakkarainen (2005) labelled - trialogical knowledge creation. In educational eResearch, these trialogical practices involve not only collaborative development of shared objects of inquiry for answering research questions, but also explicit attention and the simultaneous development of new digital epistemic infrastructures that consist of digital resources, software and conceptual tools and social structures. Initially, I introduce key eResearch notions and show some links with challenges in educational research. Next, I discuss three major eResearch affordances in detail: data and knowledge resources; data-rich and computation- intensive research methodologies; and collaborative knowledge building practices. I construct my argument on two planes. First, I draw some parallels between the nature of eResearch affordances and issues in educational research. Second, I show several gaps between eResearch notions and present knowledge practices. I conclude by discussing some immanent challenges for building better epistemic infrastructures for educational research and deliberative knowledge advancement.

Educational research and inquiry ${ }^{2}$ is a broad field, and I do not intend to argue that digital media and technologies should have similar role and place in all inquiry practices (perhaps not at all in some). I also do not claim that they could contribute to all answers and solutions. What I want to show, in the context of this discussion, is that digital media and technologies could provide possibilities to do research differently and to investigate in new ways some old and new educational issues that cannot otherwise be explored and therefore not solved.

\section{eResearch: Notions, Visions and Potential}

In the broadest sense, eResearch refers to scholarly practices enabled or enhanced by the combination of three developments of advanced digital technologies: large integrated data repositories; high-performance computing; and high-speed computer networks (Wouters, 2005). New research opportunities typically arise from the possibilities to consolidate distributed raw data and other knowledge resources, technological capacities and human expertise and, consequentially, to work together on more global big-picture problems or conduct explorations at new levels of detail (Figure 1) $)^{3}$. Examples of such research problems range from the modelling of climate change and the exploration of human genome structures, in physical sciences, to the studies of large linguistic corpuses, integrated social policy analyses and forecasts of educational systems' in humanities and social sciences (Blanke, Hedges, \& Dunn, 2009; Dzemyda, Saltenis, \& Tiesis, 2003; Hey, Tansley, \& Tolle, 2009). 


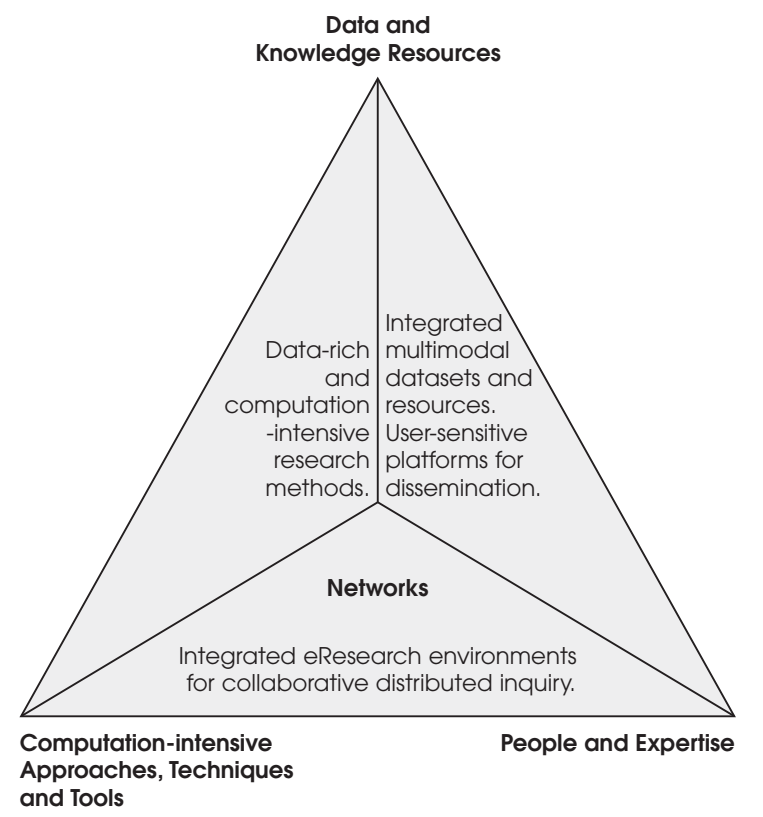

Figure 1. Main eResearch Elements and Affordances

With the evolution of digital media and technologies, the distinction between eResearch practices that fundamentally rely on advanced "high-end" technologies and everyday scholarly eResearch practices that apply an ordinary desktop computer connected to internet have become increasingly blurred (cf. Anderson \& Kanuka, 2003; Atkins et al., 2003). ${ }^{4}$ Similarly, eResearch role in different inquiry practices has become more varied and its impact on the ways in which knowledge is produced has been different and sometimes highly debated. On the one hand, eResearch is perceived as an element enhancing existing methodological and theoretical research traditions and practices (Hine, 2005; Wouters, 2005). On the other hand, there is a strong argument that eResearch has given birth to an epistemically coherent research paradigm of data-intensive scientific discovery (Hey et al., 2009). Furthermore, there is an ongoing debate over the impact of digital media and technologies on the nature of scholarship arguing that existing moral, cultural and organisational frames that historically operated in more self-contained real world research environments are not a good fit for the more distributed and cross-disciplinary eResearch practices of the digital world (Borgman, 2007; Greenhow et al., 2009).

While there are some pockets of successful eResearch practices, the actual levels and ways of adoption vary both across and within disciplines (e.g., see Hine, 2006; Jankowski, 2009). Even so, the rapid adoption of a number of eResearch affordances across domains - such as e-journal databases - and substantial embracement of digital technologies in some research areas that were historically rather distant from technologies - such as linguistics, arts and archaeology - have signalled that eResearch 
might have the potential to contribute to a rather broad spectrum of research questions and inquiry practices, in various fields, including education (e.g., Carmichael, 2007; Pea, 2006; Romero \& Ventura, 2007). Nevertheless, these eResearch contributions might be more carefully nuanced and specific to the issues and disciplinary practices than the initial techno-optimistic visions (e.g., Atkins et al., 2003) tended to state.

Many scholars in science and technology studies have argued that research technologies and our knowledge creation practices mutually shape each other (Schroeder \& Fry, 2007; Woolgar \& Coopmass, 2006; Wouter et al., 2008). While inscription technologies shape the ways in which data and knowledge are represented, created and shared (Voithofer, 2005), existing research questions and practices influence the choice of technologies and ways they are used (Wouters, 2005). The central question for education, as for other social sciences, is "how it is possible to develop novel ways of knowledge creation ... by utilising and adapting e-research concepts, instruments and ways of working" (Wouters, 2005, p. 4).

\section{Linking eResearch Affordances and Issues in Educational Inquiry}

In the recent years, there has been ongoing debate over the numerous issues in educational research, naming among many others such limitations as a lack of rigour, theoretical incoherence, irrelevance to schools, lack of involvement of teachers, inaccessibility and poor dissemination, failure to produce cumulative research findings, ideological bias and poor cost effectiveness (e.g., Kaestle, 1993; Whitty, 2006). While educational problems are "wicked" (Conklin, 2006) and do not easily lend themselves to being fully understood, at least some of the limitations come from the rather fragmented nature of educational research and inquiry practices. To summarise some insights of other scholars (Dede, 2009; McWilliam \& Lee, 2006), heterogeneity of research traditions and methods and low compatibility of techniques result in difficulties analysing data from multiple perspectives and, as a result, producing more ecological evidence. Even if some data could be (re)analysed from several methodological or social perspectives, limited collaboration and data sharing confine such opportunities. Furthermore, solitary research cultures and processes often restrict the possibilities to integrate methodological and stakeholder perspectives and, as a result, to produce findings relevant to schools, decision-makers and consequential stakeholders. Finally, the narrow focus of scholarly dissemination on an academic audience limits the impact of research on educational practice and policy. These limitations together restrict opportunities for more cumulative and iterative use-oriented knowledge building. Putting these issues and eResearch sideby-side, one could make a justified projection that eResearch might offer some new affordances for educational inquiry (Figure 2). I will discuss each of these three eResearch affordances in the next sections. 


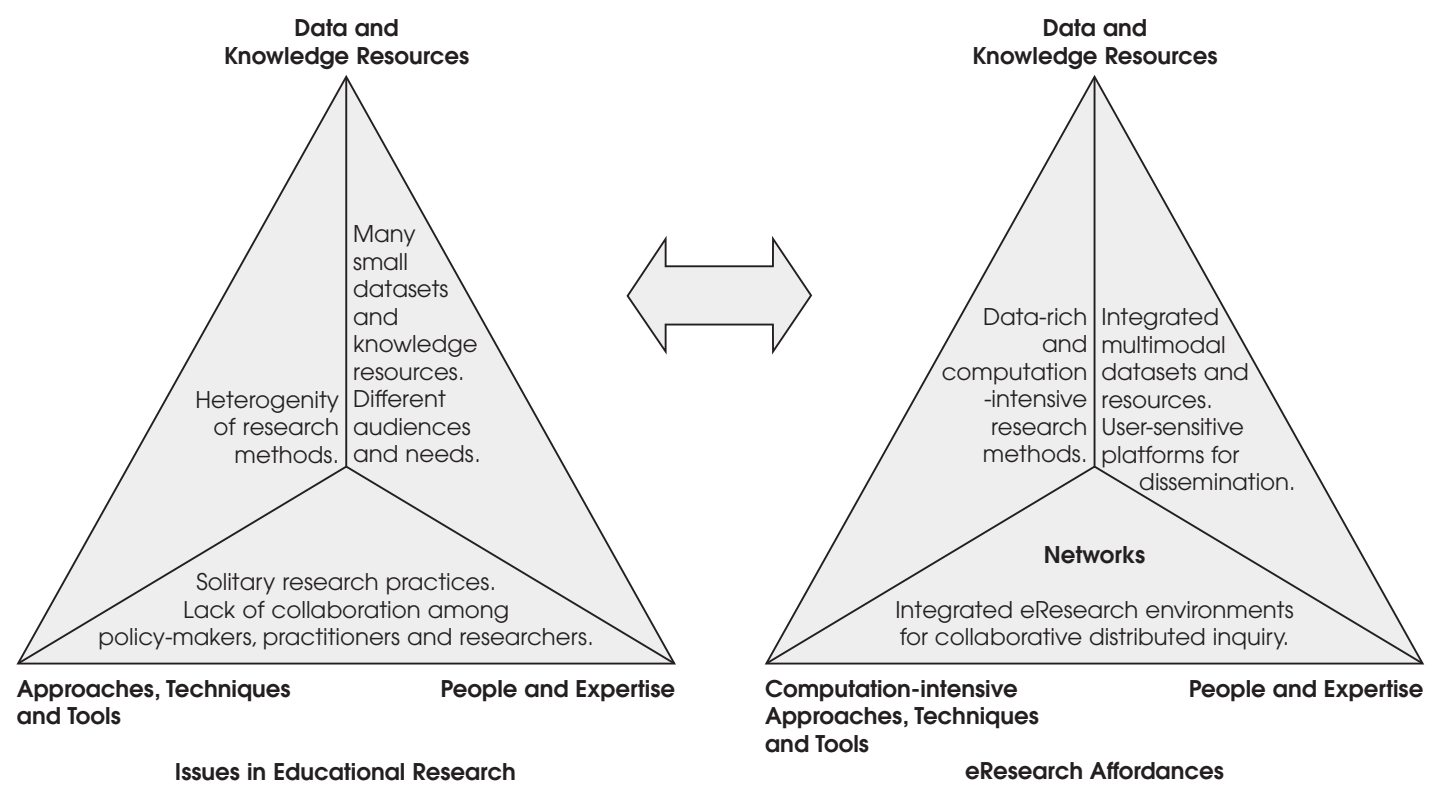

Figure 2. Common Issues in Educational Research and eResearch Affordances

\section{Learning “Data Deluge": Taking Data Seriously}

Many issues in educational research pertain to data. For example, debates about the quality of "what works" analyses, the transparency of qualitative research and the usefulness of the findings for teaching practice or decision-making, at the end of the day, converge to the issues of the quality of published data or availability of raw data (cf. Eisner, 1997; Freeman et al., 2007; Schneider, 2004; Slavin, 2008). On the contrary, educational practices and research studies generate increasingly larger volumes of more complex data that far exceed human capabilities for manual analysis, ${ }^{5}$ do not fit linear format of printed media and exceed the limited space in printed academic journals.

Analysed and published data are inevitably selective re-representation of a small amount raw data originally collected in the field (Woolgar \& Coopmass, 2006). They "lock in" numerous methodological and pragmatic choices made at different stages of research and limit subsequent interrogation. Data that is abstracted and prepared for publishing does not necessarily provide sufficient information for those who would look at the raw representation of the phenomenon from different epistemic or social perspectives, and does not allow one to zoom in from the abstraction back to the original record. For example, synthesised results from the analysis of a classroom innovation published in an academic paper might have a limited use for a teacher who might be interested to implement similar innovation in her classroom and would benefit from access to the lesson resources or video record analysed in the study, yet not available in the publication. Similarly, data prepared for a teacher might have little value for a parent or other stakeholder who might be more interested in students' 
accounts of their experiences that were captured in the interviews rather than in pedagogical nuances. While educational researchers still debate whether there is or not such thing as raw data uncontaminated by human thought or action (cf. Erickson, 2006; Freeman et al., 2007), to put it boldly, materials collected or recorded in the field, if shared, have a potential for generating more knowledge than one chooses to extract and enact in a publication or practice. This argument is illustrated in Figure 3.

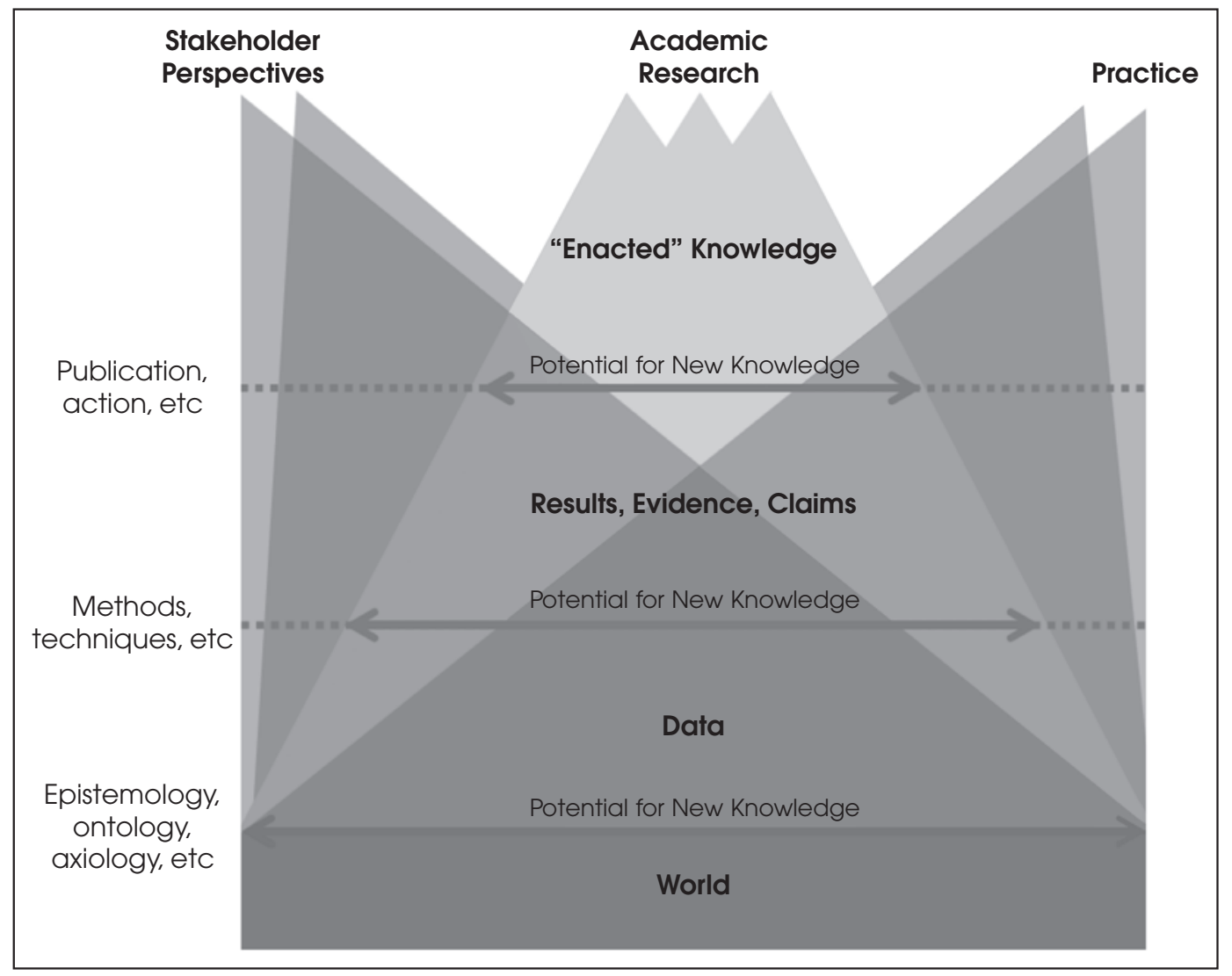

Figure 3. From Real World to Enacted Knowledge

With the proliferation of digital recording devices and eLearning, technologies much of the data gets captured in digital format, and, thus, is ready for further technologyenhanced management, analysis and dissemination. Cheap digital storage creates opportunity to store and publish almost unlimited amounts of data. Furthermore, data and knowledge resources inscribed in digital media have different features from the data inscribed in physical artefacts and provide new possibilities for analysis, presentation and dissemination. Voithoffer (2005), referring back to the theories of digital materialism, describes five primary ways in which digital media are sites for computerisation of culture and knowledge: numerical representation, modularity, automation, variability and transcoding ${ }^{6}$. To put his argument simply, a digital format allows numerous human 
and automated re-combinations, transformations, presentations and customisations of data and knowledge and, hence, allows one to investigate the same objects of inquiry inscribed in digital media from multiple methodological and social perspectives. The digital form affords one with opportunities to represent knowledge and the results of inquiry using multiple media languages (such as video and text) and human discourses (such as teacher, decision maker, student and parent); and, when needed, to backtrack from the abstracted representations to raw data.

The idea to create data clouds or shared data banks and make them accessible via multiple interfaces to different audiences is not new; and some disciplines have been very successful pooling together large amounts of heterogeneous data resources for collaborative exploration. For example, the astronomy's portal SkyServer provides free access to the integrated from many sources Sloan Digital Sky Survey (SDSS) astronomy database that includes over 80 million stars, galaxies, and quasars (SkyServer, 2010). A variety of tools for searching, visualizing and exploring SDSS make this database accessible for professional and "citizen scientists". Similarly, publishing data in open peer-reviewed data repositories, interlinking them with journal publications or creating presentations of findings for different audiences are well-established practices in some disciplines?

These ideas are not completely new for education. For example, data that comes from well known TIMSS and PIRLS international studies are also publicly available for further interrogation (see IEA, 2010). Nevertheless, such cases are few and are typically based on few well-structured datasets. A more challenging question is how to share and integrate heterogeneous datasets needed for cumulative research, such as a dataset for a longitudinal research on teacher education envisioned in the ACDE's (2009) scoping study. While one might argue that the issues of anonymity, confidentiality and security of personal and learning data make data sharing problematic in social studies (cf. Bishop, 2005; Broom, Cheshire, \& Emmison, 2009; Carusi \& Jirotka, 2009; Kelly, 2009; Parry \& Mauthner, 2005), these ethical questions are likely to have well thought sensible solutions. At least some similar fields, such as social welfare, medicine and health have been rather successful overcoming trust and security issues and have created shared data infrastructures of highly confidential data for scientific research and practice (Burton, Purvin, \& Garrett-Peters, 2009; Jirotka et al., 2005).

A rather different serious challenge in education is what Cole (2008) has labelled as an "indifference to data" - limited explicit attention to data and how they are produced. For example, one common issue in understanding causal explanations of learning phenomena is the importance of the context (Freeman et al., 2007; KoroLjungberg et al., 2009; Maxwell, 2004); and, in order to make data re-usable and open for meaningful re-interpretations, the context that led to the data and the context in 
which these data were produced need to be recorded and shared. Such data "provenance" or "pedigree" records are rarely explicitly produced in educational research. In fact, social researchers have almost no vocabulary and norms for articulating and sharing raw data or data about the data and their contexts ${ }^{8}$. The integration of data, as Cole (2008) has noticed, has not occurred by accident even in well structured scientific domains; and maintaining the coherence of data and outputs requires one's willingness and explicit efforts to prepare data for sharing and share.

In the context of massive school computerisation, one more specific type of data needs more explicit attention - "digital traces" of learning activities that are (or could be) automatically captured in learning environments (Borgman et al., 2008; Schooneboom et al., 2007). When much of the interaction happens in digital media and distributed over physical settings, learning phenomena become almost inaccessible for direct observation for both teachers and researchers. Nevertheless, these interactions leave an extensive digital trace; and more comprehensive understanding of such large scale political, social and cognitive phenomenon - such as the Australian Digital Education Revolution (Commonwealth of Australia, 2008) becomes incomplete, if not impossible, without making sense of these "machine observations". Data collected for technical purposes do not necessary come in a form that is suitable for answering educational questions. Nevertheless, these traces often have been either ignored or taken as given in educational research and there has been little attention to the possibilities to get right (or better) data for a problem. This indifference to digital traces is another indication of a larger issue - educational researchers try to produce better answers to old and new research questions, but put relatively little effort into understanding data and creating better data infrastructures and, as I subsequently argue, inquiry tools that are the key drivers of innovation in many scientific and practical fields.

\section{Data-rich Research Methods: Shapes of "the Fourth" Paradigm in Educational Research}

In the history of scientific inquiry there have been several major shifts: from empirical science, based on the description of natural phenomena thousands years ago; to theoretical science, based on the logical reasoning, measurements, experimentation and mathematical manipulation, hundreds years ago; to computational science, based on the simulations and modelling of complex phenomena several decades ago (Jackson, 2000). Developments of new research instruments for the measurement and observation and, later, for computation and modelling, have been at the core of these two scientific revolutions. eResearch gave rise to the the fourth scientific paradigm of data exploration, based on the synthesis of theories, experiments and computation 
using large data set exploration techniques (Hey et al., 2009). The development of software and conceptual tools for digital data management and data-intensive knowledge discovery has been at the core of this shift.

The history of educational research cannot be reduced to technical choices of method; nevertheless methodological advancements in educational inquiry at least in part have been coupled with the advancements in research instruments for empirical observation and measurement and at least broadly have mirrored the progress from the descriptive to hypothesis and theory driven quantitative and qualitative research (e.g., Lagemann, 2000; Shulman, 1981). While the importance of (conceptual) research tools in educational inquiry has been well acknowledged, the role of digital technologies has not been as radical and as widespread in educational research as in physical sciences; and the shape of the third and the fourth paradigms in educational research is a contentious question?. For example, hard system modelling, despite its broad application in economic, policy and other social fields and increasing interest in complexity perspectives in education (e.g., Jacobson \& Wilensky, 2006; Radford, 2006), has seen very few applications in educational research. Some data-intensive research approaches - such as knowledge discovery in databases, typically known as educational data and text mining - have made significant inroads ${ }^{10}$, but most progress has been made in advancing mining algorithms and little educational knowledge. As an indication, all 40 contributors to the book "Data mining in eLearning" (Romero \& Ventura, 2006) come from computer science and related fields, while none of the papers published in the Australian Educational Researcher over the last seven years mentions data mining ${ }^{11}$.

The complexity of educational systems and the recent learning data deluge do not allow one to think that education might have no issues that are suited for computational modelling and data-rich discovery. On the contrary, the more pragmatic and groundedin-data logic of these methodological approaches appears to be well suited for a practical domain such as education. For example, data and text mining involves an iterative process of sniffing through large amounts of data and discovering patterns and relationships (Zhao \& Luan, 2006). This exploration combines interpretative investigation with scientific data-based reasoning. Nevertheless, the logic that guides such knowledge discovery contrasts with both positivistic and interpretative research traditions. For example, data miners start their exploration with no a priori assumption about the existence or nature of relationships in data. In contrast to statisticians, they do not focus on establishing generalisations across samples and do not judge their findings on the basis of statistical significance; rather they try to detect different possible patterns and idiosyncratic behaviours and judge their findings on the basis of practical significance. Such open opportunistic logic is essentially unrecognised in educational inquiry. 
Nevertheless, computation-intensive and data-rich research techniques involve one's work with transformed data representations mediated by technology that are typically less intuitive than purposefully collected and manually processed data. Moreover, explorations of social phenomena in digital spaces often require researchers to combine conventional methodological traditions with data-driven technology-mediated ways of inquiry (Hine, 2005; Markham \& Baym, 2009). For example, a virtual ethnographer, who explores a large and distributed across physical settings and time online learning community, has to go beyond direct observation and authentic thick experience and engage with more fragmented and shallow ways of technology-mediated observation, such as visual representations of social networks or the exploration of digital traces. Such work on the methodological boundaries of rather contrasting inquiry traditions presents a serious epistemic challenge.

Ultimately, a handful of eResearch methods have challenged the social organisation of knowledge production involving citizen scientists into a legitimate scientific discovery. For example, recent astronomical discoveries about the rotation of galaxies have been made by a network of children, teachers and other lay explorers, who collaboratively over a one year period produced more than 50 million classifications of a million galaxies that later have been only summarised by professional scientists (Lintott et al., 2008). Similarly, in education, research planning and, particularly, data analysis and interpretation that have been rather exclusive areas of monologic academic work have become increasingly a collaborative practice (Armstrong et al., 2005; Carmichael, 2007; Laterza, Carmichael, \& Procter, 2007; Pea, Lindgren, \& Rosen, 2008; Ritchie \& Rigano, 2007). Collaborative research platforms and data analysis tools, such as distributed video analysis, provide possibilities to involve participants and other stakeholders in different research stages (Carmichael, 2007; Pea et al., 2008) ${ }^{12}$. Such practices, however, are rare.

The main challenge, however, is that computational and data-rich methods as well as socially rich forms of inquiry present rather different ways for generating knowledge that are trans-disciplinary in a deep ontological and epistemological sense. They require researchers to understand how "e" works, how it could be combined with disciplinary issues, conceptual knowledge, social organisation of inquiry and what kinds of knowledge these combinations could produce. This blending of professional expertise with digital technology-mediated ways for constructing knowledge inevitably encourages more collaborative configurations of social fabric for knowledge production, and new notions of scholarship.

\section{Collaborative Inquiry: Shapes of Digital Scholarship}

As Borgman (2007) has argued, the main purpose of eResearch is to enable new forms of scholarship that are more data and information-intensive, distributed, collaborative, 
and multidisciplinary. Discussions about how digital media and technology-mediated ways of knowledge production affect the role and practices of academia have produced an array of notions of "digital scholarship" that vary in terms of their focus on different practices and outputs ${ }^{13}$. One of the classical definitions proposed by the American Council of Learned Societies (2006) has emphasised new types of knowledge products and included in the notion of digital scholarship the following practices:

- Building a digital collection of information for further study and analysis;

- Creating appropriate tools for collection-building;

- Creating appropriate tools for the analysis and study of collections;

- Using digital collections and analytical tools to generate new intellectual products;

- Creating authoring tools for these new intellectual products, either in traditional forms or in digital form. (p. 7)

In short, according to this notion, digital scholarship has a strong epistemic focus, but includes a whole range of new intellectual products that are not necessarily the definitive answers or solutions, but are part of an epistemic infrastructure for building digital knowledge collaboratively.

In addition, digital media and technologies have expanded scholarly dissemination opportunities, threatening the monopoly of commercial publishers and established scientific communities and making publishing quicker, more transparent and less restrained by one-way textual format (Poschl, 2004; Seringhaus \& Gerstein, 2007; see also "Scholarly communication" section in Hey et al., 2009). For example, in addition to many self-publishing opportunities in wikis, blogs and other web spaces, open publishing and open peer-review make traditional blind processes fully visible for the audience (Poschl, 2004). Further, papers that are open for continuous peer commentary and discussion have become a viable peer-review and dissemination alternative.

More recent developments in participatory technologies have generated a set of new notions of scholarship with stronger emphasis on social knowledge practices. As Greenhow et al. (2009) indicate, the main qualities of social scholarship are "openness, conversation, access, sharing and transparent revision" (p. 253); while "validity of knowledge in Web 2.0 environments is established through peer review in an engaged community, and expertise entails offering syntheses widely accepted by the community" (p. 247). Roughly speaking, digital scholarship includes practices that are beyond direct contribution to conceptually new knowledge, such as engaging in debates, the repackaging of existing knowledge into new intellectual products and bringing them beyond traditional spaces of academia. 
In short, these digital shifts place a different emphasis on cognitive and social values in knowledge work. Educational scholars, however, have been more successful embracing (some of) the opportunities for social scholarship than for more cognitively rigid knowledge production (see discussion Greenhow et al., 2009; Zhang, 2009). As Zhang (2009) comments, participatory approaches and tools - such as wikis - are, "strong in supporting knowledge sharing [Italic added], but relatively vague and weak in advancing [italic original] community of knowledge" (p. 274). Innovation requires sustained commitment to progressive advancement of knowledge and intellectual rigour; and sharing loosely related ideas or voting for the most popular idea does not always contribute to the design of a practical solution or formulation of a higher-level idea. Present digital resources and Web 2.0 tools are relatively weak in their support of epistemic commitment and smarter knowledge work of educational scholars and practitioners. In contrast, scholarly practices with a stronger epistemological focus, such as creating tools for inquiry, contributing data to repositories or creating and maintaining repositories of educational data, have not gained much attention, making more collaborative knowledge building practices little supported by collaborative knowledge building infrastructure.

\section{Educational eResearch as a Trialogical Inquiry: Some Reflections on Missing Links}

The classical division between acquisition and participation (Sfard, 1998), that was later relabelled by Paavola and Hakkarainen (2005) as monological and dialogical approaches to knowing, can be seen not only in educational accounts of learning, but also in our interpretations of scholarly practices, including digital scholarship. On a deep cognitive level, monological knowledge work has a strong presence in digital practices of educational researchers. As an indicator, an eResearch survey conducted in NSW found that about two thirds of educational researchers at least occasionally use SPSS, NVivo and some other individualistic software on which they could offload some traditional cognitive tasks, but less than $7 \%$ ever use collaborative virtual research environments ${ }^{14}$. On the public discourse level, the attention to dialogical practices - such as open publishing, social networks and other participatory practices - has overshadowed the monological approaches (cf., Dede, 2009; Greenhow et al., 2009; Zhang, 2009). In both cases the attention to how digital media and technologies could support sustainable cognitively nontrivial collaborative educational inquiry has been limited.

As Paavola and Hakakrainen (2005) have argued, innovative knowledge communities advance knowledge by engaging in trialogical knowledge work - collaboratively developing shared "mediated objects" and "mediated artefacts". While they create social 
structures and collaborative processes that support knowledge sharing, they also maintain a strong commitment to generating ideas and conceptual knowledge. eResearch platforms and networks provide a medium for instantiating current understanding, interacting and advancing collaboratively shared conceptual objects, but they do not offer a readily made digital infrastructure - including data and tools - for educational inquiry.

Shared data and knowledge resources provide the backbone for more collaborative and open knowledge building. Nevertheless, research that could be useful, integrated and re-used by others requires an explicit attention to sharing, and neither data nor research processes will become more accessible or transparent just by putting it all online. One of the major (intellectual) challenges for the educational research community is to construct shared vocabularies and grammars appropriate for describing different kinds of knowledge work and different sorts of intellectual products. The actual use of these grammars in research practices is the next (social) challenge.

Technological artefacts and computers could be useful for assisting with or doing some traditional cognitive tasks (such as calculating or text processing); nevertheless they also embody knowledge that is not accessible to humans directly and are able to perform cognitive tasks that humans cannot do. In scientific practices, digital technologies have increasingly gained the status of cognitive partners (Nersessian, 2009). Computationintensive modelling and data-rich research methods, in essence, represent this partner's role of digital technologies in educational research. For example, humans cannot make much sense from long hours of classroom video observations or online learning data without seeing and interacting with computer visualisations, nor can computers create meaningful data representations without human involvement. This partner's role of digital technologies has been little realised and little used in educational inquiry.

An important aspect of experimentation that leads to discoveries in scientific laboratories is building, improving and customising these cognitive partners. In educational research, rather differently, digital research tools and infrastructures are, by and at large, taken as immutable and often constraining. The major challenge is that such cognitive partners cannot be built or tweaked to answer research questions by computer experts without cognitive partnership of educational researchers who know research questions and conceptual frames of the field. Furthermore, shared data and technology infrastructures for educational inquiry are not bounded to one research team or laboratory or academic community, to include decision makers, practitioners and consequential stakeholders, such as students and parents. What kind of understanding and expertise do educational researchers need about digital media structures and computer languages in order to be able to engage with such partnerships with computers and computer experts? What does it mean to build or tweak a shared 
cognitive partner that crosses the boundaries of laboratories, epistemic communities and social discourses?

As the NSF report (Borgman et al., 2008) points out:

Humans reason differently in STEM [science, technology, engineering and mathematics] domains - and learn differently - when the knowledge representational systems for expressing concepts and their relationships are embodied in interactive computing systems, rather than historically dominant text-based or static graphical media. (p. 29)

In contrast to the numerous studies of knowledge work in scientific laboratories (e.g., Knorr-Cetina, 1999; Nersessian, 2009), the nature of knowledge work in educational research has been little researched, not only in digital, but also in the physical world. How do educational researchers and others involved in inquiry make sense, use and advance their inquiry frameworks and tools; how do they interact with them and make their decisions; in what kinds of social interactions do they engage when they create knowledge? Unless we understand the "nitty gritty" of these often diverse nondigital and digital knowledge practices better, it might be difficult to think about how we could build shared (digital and conceptual) frameworks and infrastructures for collaborative knowledge building.

Finally, in the context of the massive digitalisation of culture, knowledge, and learning, how much of the educational research could still have an ecological validity without researching the digital part of it? What kinds of values, knowledge and capacities should be included in a standard "epistemic toolbox" of an educational researcher or teacherresearcher who needs to understand learning in both worlds and make numerous transontological, trans-epistemic and trans-cultural choices while researching them?15

As Eisner (1997) argues "We tend to seek what we know how to find" (p. 7). One of the biggest challenges for educational community is to create an epistemic infrastructure that is beyond this zone.

\section{Endnotes}

1 Different terms are used to refer to similar, advanced-technology enhanced research infrastructures and practices in different countries and disciplinary contexts - such as, "eScience", "eHumanities" and "eSocial sciences", in the UK; "Cyberinfrastructure" in the US; and "eInfrastrucure" and "the Grid" in the European Union (O'Brien, 2005).

2 In this paper, I do not make a distinction between scientific inquiry (i.e., research) and all other forms of scholarly, professional and technical inquiry. I refer by these 
terms to different shades of principled deliberative ways to investigate something that is not adequately understood in order to advance knowledge or produce a practical solution.

3 Specifically, networks provide a possibility to interconnect distributed small and large datasets and other knowledge resources stored in different digital media (such as documents, videos and other digitalised artefacts) that could be used for integrated research, secondary analysis and evidence-based decisions. Further, high-performance computing allows for the employment of new data analysis techniques that are required to perform numerous computations and data transformations, such as the modelling of complex systems, exploration of patterns in large data sets using knowledge discovery algorithms, visualisation of interactions in large social networks or painstaking video analysis of complex social interactions. Finally, networks allow researchers to engage with new collaborative distributed inquiry practices, such as joint research design and writing or remote data analysis in virtual research environments.

4 In this paper, I use term "eResearch" broadly to refer to a whole range of ICT-enhanced research approaches and practices: from advanced high-speed computation-intensive collaborative research (e.g., Atkinson, 2003; Hey et al., 2009) to more conventional ICTenhanced research, such as the use of digital libraries and Web 2.0 collaboration (e.g., Anderson \& Kanuka, 2003; Greenhow et al., 2009).

5 As an illustration of this issue, the integrity of design-based research and other qualitative inquiries is challenged by the Bartlett effect, of selecting for analysis and, consequently, for presentation only those data that support one's favourite hypothesis (Brown, 1992); traces of students' eLearning automatically captured in digital learning environments create "learning data deluge" (Borgman et al., 2008).

6 According to Voithoffer (2005, in which he cites Manovich (2001)), numerical representation (e.g. digitalisation) allows one to manipulate and program digital inscriptions and, in this way, provides people with possibilities to recombine and customise these representations in many ways. Modularity allows one to combine and recombine media objects without losing their individual characteristics, and present them in various configurations through diverse interfaces. Automation allows one to generate user-defined queries and pre-programmed interactions and, in this way, enables people to simplify complex processes of storing, searching and retrieving information. Variability allows one to separate of the content from the presentation and to derive the latter from the human or machine manipulation and interaction. In this way, media objects and data could be presented in user-sensitive multiple ways. Transcoding allows one to blend computer languages (e.g., algorithms, data structures), media languages (e.g., visual composition, genre) and other human discourses (e.g., research, educational and political discourses) in different ways. All of these features allow one to recombine data in various ways without loosing the link to its original non-transformed form. 
7 For example, before their papers get published in the highly rated Plos Computational Biology journal (PLoS, 2010), computational biologists have to deposit data sets associated with their publication in an open biology repository, such as Worldwide Protein Data Bank - PTB (wwPTB, 2010). Furthermore, some authors upload to SciVee portal a "pubcast" or other media resources in which they explain and discuss their scientific findings further with professional and non-professional audiences (see SciVee, 2010).

8 In contrast, educational researchers have a relatively well established vocabulary and norms of sharing information about their argumentative grammars (i.e., method) that justify their data and link evidence to the claims. More detailed discussion of these questions and the provenance of educational data can be found in Reimann and Markauskaite (2010) and Markauskaite and Reimann (2008b).

9 More detailed discussion about technology-mediated research methods for educational inquiry can be found in Markauskaite (in press).

${ }^{10}$ Published solid books, annual conferences and recently established "Journal of Educational Data Mining" are just few manifestations of advancements in educational data mining. More information can be found on the International Working Group on Educational Data Mining website (EDM, 2010).

${ }^{11}$ The Australian Educational Researcher's full text archive 2003 (30.1)-2009 (36.1) has been interrogated using Google query "data mining", site:http://www.aare.edu.au/aer

${ }^{12}$ Further ideas about how eResearch could be used to enhance teacher-researcher innovation and inquiry can be found in Markauskaite and Reimann (2008a).

${ }^{13}$ In academic discourses, a range of other terms have been used to describe different shades of "digital scholarship", such as "eScholarship", "social scholarship" and "Scholarship 2.0".

${ }_{14}$ These results are based on an eResearch survey data (as at 15 January 2010) that has been conducted at seven NSW universities in 2009-2010. See Markauskaite, Aditomo and Hellmers (2009) for the 2009 year report.

${ }_{15}$ Digital knowledge and eResearch raise new questions of institutional control, power and inequity. For example, some of them have been already evident in the recent debates of MySchool website, which allows to compare performance of all Australian schools (My School, 2010). While socio-political agendas behind eResearch have been in the background of this paper only, these questions are an integral part of digital scholarship. I believe, this is one of the main "trans-epistemic" and "trans-cultural" questions that those who will create "digital epistemic infrastructures" will need to answer responsibly.

\section{Acknowledgements}

I wish to thank Nicola Johnson, Shannon Kennedy-Clark, Michael Jacobson and Raewyn Connell for their help shaping this paper. Without their careful reading and feedback this paper would never become what it is now. All claims and mistakes, nevertheless, are my sole responsibility. 


\section{References}

Australian Curriculum, Assessment and Reporting Authority (ACARA). (2010). My school website. Retrieved August 23, 2010, from Australian Curriculum, Assessment and Reporting Authority web site: http://www.myschool.edu.au.

Australian Council of Deans of Education (ACDE). (2009). Data repository for teacher education scoping study. Australia: The Australian Council of Deans of Education.

American Council of Learned Societies Commission (ACLS). (2006). Our cultural commonwealth: The final report of the American council of learned societies commission on Cyberinfrastructure for the humanities and social sciences. Retrieved August 23, 2010, from ACLS website: http://www.acls.org/uploadedFiles/ Publications/Programs/Our_Cultural_Commonwealth.pdf

Anderson, T., \& Kanuka, H. (2003). E-research: Methods, strategies and issues. Boston: Pearson Education Inc.

Armstrong, V., Barnes, S., Sutherland, R., Curran, S., Mills, S., \& Thompson, I. (2005). Collaborative research methodology for investigating teaching and learning: The use of interactive whiteboard technology. Educational Review, 57, 457-469.

Atkins, D. E., Droegemeier, K. K., Feldman, S. I., Garcia-Molina, H., Klein, M. L., Messerschmitt, D. G., et al. (2003). Revolutionizing science and engineering through Cyberinfrastructure. Report of the National Science Foundation blueribbon advisory panel on Cyberinfrastructure. Arlington, VA: Directorate for Computer and Information Science and Engineering, National Science Foundation.

Bennett, S., Maton, K., \& Kervin, L. (2008). The "digital natives" debate: A critical review of the evidence. British Journal of Educational Technology, 39(5), 775-786.

Bishop, L. (2005). Protecting respondents and enabling data sharing: Reply to Parry and Mauthner. Sociology, 39(2), 333-336.

Blanke, T., Hedges, M., \& Dunn, S. (2009). Arts and humanities e-science - current practices and future challenges. Future Generation Computer Systems, 25(4), 474480.

Borgman, C. L. (2007). Scholarship in the digital age: Information, infrastructure, and the internet. Cambridge, MA: The MIT Press.

Borgman, C. L., Abelson, H., Dirks, L., Johnson, R., Koedinger, K. R., Linn, M. C., et al. (2008). Fostering learning in the networked world: The cyberlearning opportunity and challenge, a 21st century agenda for the National Science Foundation. Arlington: NSF Task Force on Cyberlearning.

Broom, A., Cheshire, L., \& Emmison, M. (2009). Qualitative researchers' understandings of their practice and the implications for data archiving and sharing. Sociology, 43(6), 1163-1180.

Bransford, J. D., Brown, A. L., \& Cocking, R. R. (Eds.). (1999). How people learn: Brain, mind, experience, and school. Washington, DC: National Academy Press.

Brown, A. L. (1992). Design experiments: Theoretical and methodological challenges in creating complex interventions. The Journal of the Learning Sciences, 2, 141-178. 
Burton, L. M., Purvin, D., \& Garrett-Peters, R. (2009). Longitudinal ethnography: Uncovering domestic abuse in low-income women's lives. In G. H. Elder Jr. \& J. Z. Giele (Eds.), The craft of life course research (pp. 70-92). New York, NY: Guilford Press.

Carmichael, P. (2007). Introduction: Technological development, capacity building and knowledge construction in education research. Technology, Pedagogy and Education, 16(3), 235-247.

Carusi, A., \& Jirotka, M. (2009). From data archive to ethical labyrinth. Qualitative Research, 9(3), 285-298.

Cole, F. T. H. (2008, December 3-5). Taking "data" (as a topic): The working policies of indifference, purification and differentiation. Paper presented at the 19th Australasian conference on information systems, Christchurch, New Zealand.

Conklin, J. (2006). Wicked problems and social complexity. New York: Wiley.

Commonwealth of Australia. (2008). Success through partnership: Achieving a national vision for ICT in schools. Strategic plan to guide the implementation of the digital education revolution initiative and related initiatives. Retrieved August 26, 2010 from http://www.deewr.gov.au/Schooling/DigitalEducationRevolution/ Documents/DER\%20Strategic\%20plan.pdf

Computing Research Association (CRA). (2005). Cyberinfrastructure for education and learning for the future: A vision and research agenda. Washington, DC: Computing Research Association.

Cuban, L. (2001). Oversold and underused: Computers in the classroom. Cambridge, MA: Harvard University Press.

Dede, C. (2009). Comments on Greenhow, Robelia, and Hughes: Technologies that facilitate generating knowledge and possibly wisdom. Educational Researcher, 38(4), 260-263.

Department of Education, Science and Training (DEST). (2006). An Australian eresearch strategy and implementation framework: Final report of the e-research coordinating committee. Commonwealth of Australia: Australian Government, DEST.

Dzemyda, G., Saltenis, V., \& Tiesis, V. (2003). Forecasting models in the state education system. Informatics in Education, 2(1), 3-14.

EDM (2010) International Working Group on Educational Data Mining. Retrieved April 23, 2010, from: http://www.educationaldatamining.org

Eisner, E. W. (1997). The promise and perils of alternative forms of data representation. Educational Researcher, 26(6), 4-10.

Erickson, F. (2006). Definition and analysis of data from videotape: Some research procedures and their rationales. In J. L. Green, G. Camilli, P. B. Elmore, A. Skukauskaite \& E. Grace (Eds.), Handbook of complementary methods in education research (pp. 177-191). Mahwah, NJ: Lawrence Erlbaum Associates.

Freeman, M., deMarrais, K., Preissle, J., Roulston, K., \& Pierre, E. A. S. (2007). Standards of evidence in qualitative research: An incitement to discourse. Educational Researcher, 36(1), 25-32. 
Greenhow, C., \& Robelia, B. (2009). Informal learning and identity formation in online social networks. Learning, Media and Technology, 34(2), 119-140.

Greenhow, C., Robelia, B., \& Hughes, J. E. (2009). Learning, teaching, and scholarship in a digital age: Web 2.0 and classroom research: What path should we take now? Educational Researcher, 38(4), 246-259.

Hey, T., Tansley, S., \& Tolle, K. (Eds.). (2009). The fourth paradigm: Data-intensive scientific discovery. Remond: Microsoft Research.

Hine, C. (Ed.). (2005). Virtual methods: Issues in social research on the internet. Oxford: Berg.

Hine, C. (Ed.). (2006). New infrastructures for knowledge production: Understanding e-science. Hershey: Information Science Publishing.

IEA (2010). IEA online database. Retrieved April 23, 2010, from International Association for the Evaluation of Educational Achievement web site: http://www.ieadata.org

Jackson, E. A. (2000). The unbounded vistas of science: Evolutionary limitations. Complexity, 5(5), 35-44.

Jacobson, M. J., \& Wilensky, U. (2006). Complex systems in education: Scientific and educational importance and implications for the learning sciences. The Journal of the Learning Sciences, 15(1), 11-34.

Jankowski, N. W. (Ed.). (2009). E-research: Transformation in scholarly practice. New York, NY: Routledge.

Jirotka, M., Procter, R., Hartswood, M., Slack, R., Simpson, A., Catelijne, C., et al. (2005). Collaboration and trust in healthcare innovation: The eDiaMoND case study. Computer Supported Cooperative Work, 14(4), 369-398.

Kaestle, C. F. (1993). The awful reputation of educational research. Educational Researcher, 22(1), 26-31.

Kelly, A. (2009). In defence of anonymity: Rejoining the criticism. British Educational Research Journal, 35(3), 431-445.

Knorr-Cetina, K. (1999). Epistemic cultures: How the sciences make knowledge. Cambridge, MA: Harvard University Press.

Koro-Ljungberg, M., Yendol-Hoppey, D., Smith, J. J., \& Hayes, S. B. (2009). (e)pistemological awareness, instantiation of methods, and uninformed methodological ambiguity in qualitative research projects. Educational Researcher, 38(9), 687-699.

Lagemann, E. C. (2000). An elusive science: The troubling history of education research. Chicago: University of Chicago Press.

Lankshear, C., \& Knobel, M. (Eds.). (2008). Digital literacies: Concepts, policies and practices. New York: Peter Lang.

Laterza, V., Carmichael, P., \& Procter, R. (2007). The doubtful guest? A virtual research environment for education. Technology, Pedagogy and Education, 16(3), 249-267.

Law, N., Pelgrum, W. J., \& Plomp, T. (Eds.). (2008). Pedagogy and ICT use in schools around the world: Findings from the IEA sites 2006 study. Hong Kong: CERCSpringer. 
Lintott, C. J., Schawinski, K., Slosar, A., Land, K., Bamford, S., Thomas, D., et al. (2008). Galaxy Zoo: Morphologies derived from visual inspection of galaxies from the Sloan Digital Sky survey. Monthly Notices of the Royal Astronomical Society, 389(3), 1179-1189.

Manovich, L. (2001). The language of new media. Cambridge, Massachusetts: The MIT Press.

Markauskaite, L. (in press). Digital knowledge and digital research: What does eResearch offer education and social policy? In L. Markauskaite, P. Freebody \& J. Irwin (Eds.), Methodological choice and design: Linking scholarship, policy and practice. Dordrecht: Springer.

Markauskaite, L., Aditomo, A., \& Hellmers, L. (2009). Co-developing eResearch infrastructure: Technology-enhanced research practices, attitudes and requirements. Full technical report. Sydney: Intersect \& The University of Sydney.

Markauskaite, L., \& Reimann, P. (2008a, June 30 - July 4). Enabling teacher-led research and innovation: A conceptual design of an inquiry framework for ICT-enhanced teacher innovation. In Proceedings of the world conference on educational multimedia, hypermedia and telecommunications. ED-MEDIA 2008 (pp. 34843493). Austria, Vienna: AACE.

Markauskaite, L., \& Reimann, P. (2008b, July 24-28). Enhancing and scaling-up designbased research: The potential of e-research. In Proceedings of the international conference of learning sciences. ICLS 2008. Utrecht, The Netherlands.

Markham, A. N., \& Baym, N. K. (Eds.). (2009). Internet inquiry: Conversations about method. Los Angeles: Sage.

Maxwell, J. A. (2004). Causal explanation, qualitative research, and scientific inquiry in education. Educational Researcher, 33(2), 3-11.

McWilliam, E., \& Lee, A. (2006). The problem of "the problem with educational research". Australian Educational Researcher, 33(2), 43-60.

National Collaborative Research Infrastructure Strategy (NCRIS) Committee. (2008). Review of the national collaborative research infrastructure strategy's roadmap. Commonwealth of Australia: DEEWR.

Nersessian, N. J. (2009). How do engineering scientists think? Model-based simulation in biomedical engineering laboratories. Topics in Cognitive Science, 1(4), 730-757.

O'Brien, L. (2005). E-research: An imperative for strengthening institutional partnerships. Educause Review, 40(6), 64-77.

Paavola, S., \& Hakkarainen, K. (2005). The knowledge creation metaphor - an emergent epistemological approach to learning. Science E Education, 14(6), 535-557.

Parry, O., \& Mauthner, N. (2005). Back to basics: Who re-uses qualitative data and why? Sociology, 39(2), 337-342.

Pea, R., Lindgren, R., \& Rosen, J. (2008). Cognitive technologies for establishing, sharing and comparing perspectives on video over computer networks. Social Science Information, 47(3), 353-370. 
Pea, R. D. (2006). Video-as-data and digital video manipulation techniques for transforming learning sciences research, education and other cultural practices. In J. Weiss, J. Nolan \& P. Trifonas (Eds.), International handbook of virtual learning environments (pp. 1321-1393). Dordrecht: Kluwer Academic Publishing.

Poschl, U. (2004). Interactive journal concept for improved scientific publishing and quality assurance. Learned Publishing, 17, 105-113.

Prenksy, M. (2001). Digital natives, digital immigrants. On the Horizon, 9(5), 1-6.

Public Library of Science (PLoS). (2010). PloS computational biology: An official journal of the international society for computational biology. Retrieved April 23, 2010, from http://www.ploscompbiol.org/home.action

Radford, M. (2006). Researching classrooms: Complexity and chaos. British Educational Research Journal, 32(2), 177-190.

Reimann, P., \& Markauskaite, L. (2010). New learning - old methods? How e-research might change technology-enhanced learning research (pp. 249-272). In M. S. Khine \& I. M. Saleh (Eds.), New science of learning: Cognition, computers and collaboration in education. Dordrecht: Springer.

Ritchie, S. M., \& Rigano, D. L. (2007). Solidarity through collaborative research. International Journal of Qualitative Studies in Education, 20(2), 129-150.

Romero, A. C., \& Ventura, S. (2007). Educational data mining: A survey from 1995 to 2005. Expert Systems with Applications, 33, 135-146.

Romero, A. C., \& Ventura, S. (Eds.). (2006). Data mining in e-learning. Southampton: WITpress.

Sawyer, R. K. (Ed.). (2006). The Cambridge handbook of the learning sciences. Cambridge: Cambridge University Press.

Schleyer, T., Spallek, H., Butler, B. S., Subramanian, S., Weiss, D., Poythress, L., et al. (2008). Facebook for scientists: Requirements and services for optimizing how scientific collaborations are established. Journal of Medical Internet Research, 10(3), Retrieved April 23, 2010 from http://www.pubmedcentral.nih.gov/ articlerender.fcgi?artid $=2553246$.

Schneider, B. (2004). Building a scientific community: The need for replication. Teachers College Record, 106(7), 1471-1483.

Schooneboom, J., Levene, M., Heller, J., Keenoy, K., \& Turcsanyi-Szabo, M. (Eds.). (2007). Trails in education: Technologies that support navigational learning. Rotterdam/Taipei: Sense Publishers.

Schroeder, R. (2007). Rethinking science, technology and social change. Stanford: Stanford University Press.

Schroeder, R., \& Fry, J. (2007). Social science approaches to e-science: Framing an agenda. Journal of Computer-Mediated Communication, 12(2), article 11.

SciVee. (2010). Scivee: Making science visible. Retrieved 23 April, 2010, from http://www.scivee.tv. 
Seringhaus, M., \& Gerstein, M. (2007). Publishing perishing? Towards tomorrow's information architecture. BMC Bioinformatics, 8(1), 17.

Sfard, A. (1998). On two metaphors of learning and the dangers of choosing just one. Educational Researcher, 27(2), 4-13.

Shulman, L. (1981). Disciplines of inquiry in education: An overview. Educational Researcher, 10(6), 5-23.

SkyServer. (2010). Sloan Digital Sky Survey/SkyServer. Retrieved April 23, 2010, from http://cas.sdss.org.

Slavin, R. E. (2008). Perspectives on evidence-based research in education - what works? Issues in synthesizing educational program evaluations. Educational Researcher, 37(1), 5-14.

Smeyers, P., \& Depaepe, M. (2007). Educational research: Networks and technologies. The Netherlands: Springer.

Underwood, J., Smith, H., Luckin, R., \& Fitzpatrick, G. (2008). E-science in the classroom - towards viability. Computers E Education, 50(2), 535-546.

van Dijk, J. A. G. M. (2005). The deepening divide: Inequality in the information society. Thousand Oaks, CA: Sage.

Voithofer, R. (2005). Designing new media education research: The materiality of data, representation, and dissemination. Educational Researcher, 34(9), 3-14.

Whitty, G. (2006). Education(al) research and education policy making: Is conflict inevitable? British Educational Research Journal, 32(2), 59-176.

Woolgar, S., \& Coopmass, C. (2006). Virtual witnessing in a virtual age: A prospectus for social studies of e-science. In C. Hine (Ed.), New infrastructures for knowledge production: Understanding e-science (pp. 1-25). Hershey: Information Science Publishing.

Wouters, P. (2005, June 22-24). The virtual knowledge studio for the humanities and social sciences. Paper presented at the first international conference on e-social science, Manchester, UK.

Wouters, P., Vann, K., Scharnhorst, A., Ratto, M., Hellsten, I., Fry, J., et al. (2008). Messy shapes of knowledge - STS explores informatization, new media, and academic work. In E. J. Hackett, O. Amsterdamska, M. Lynch \& J. Wajcman (Eds.), The handbook of science and technology studies (pp. 319-352). Cambridge, MA: MIT Press.

Wyatt, S., Henwood, F., Miller, N., \& Senker, P. (Eds.). (2000). Technology and in/equality: Questioning the information society. London: Routledge.

wwPTB. (2010). Worldwide protein data bank. Retrieved April 23, 2010, from http://www.wwpdb.org/.

Zhang, J. (2009). Towards a creative social web for learners and teachers. Educational Researcher, 38(4), 274-279.

Zhao, C.-M., \& Luan, J. (2006). Data mining: Going beyond traditional statistics. New Directions for Institutional Research, 131, 7-16. 